\title{
Relative contribution of ecological and biological attributes in the fine-grain structure of ant-plant networks
}

\author{
Cecilia Díaz-Castelazo ${ }^{\text {Corresp., } 1}$, Cristian A. Martínez-Adriano ${ }^{1,2}$, Wesley Dáttilo ${ }^{3}$, Victor Rico-Gray ${ }^{4}$ \\ 1 Red de Interacciones Multitróficas, Instituto de Ecología, A.C., Xalapa, Veracruz, México \\ 2 Facultad de Ciencias Forestales, Universidad Autónoma de Nuevo León, Linares, Nuevo León, México \\ 3 Red de Ecoetología, Instituto de Ecología, A.C., Xalapa, Veracruz, México \\ 4 Instituto de Neuroetología, Universidad Veracruzana, Xalapa, Veracruz, México \\ Corresponding Author: Cecilia Díaz-Castelazo \\ Email address: diazcastelazogm@gmail.com
}

Background. Ecological communities of interacting species analyzed as complex networks have shown that species dependence on their counterparts is more complex than expected at random. As for other potentially mutualistic interactions, ant-plant networks mediated by extrafloral nectar show a nested (asymmetric) structure with a core of generalist species dominating the interaction pattern. Proposed factors structuring ecological networks include encounter probability (e.g. species abundances and habitat heterogeneity), behavior, phylogeny, and body size. While the importance of underlying factors that influence the structure of ant-plant networks have been separately explored, the simultaneous contribution of several biological and ecological attributes inherent to the species, guild or habitat level has not been addressed. Methods. For a tropical seasonal site we recorded (in 48 censuses) the frequency of pairwise ant-plant interactions mediated by extrafloral nectaries (EFN) on different habitats and studied the resultant network structure. We addressed for the first time the role of mechanistic versus neutral determinants at the 'fine-grain' structure (pairwise interactions) of ant-plant networks. We explore the simultaneous contribution of several attributes of plant and ant species (i.e. EFN abundance and distribution, ant head length, behavioral dominance and invasive status), and habitat attributes (i.e. vegetation structure) in prevailing interactions as well as in overall network topology (community). Results. Our studied network was highlynested and non-modular, with core species having high species strengths (higher strength values for ants than plants) and low specialization. Plants had higher dependences on ants than vice versa. We found that habitat heterogeneity in vegetation structure (open vs. shaded habitats) was the main factor explaining network and fine-grain structure, with no evidence of neutral (abundance) effects. Discussion. Core ant species are relevant to most plants species at the network showing adaptations to nectar consumption and 
deterrent behavior. Thus larger ants interact with more plant species which, together with higher dependence of plants on ants, suggests potential biotic defense at a community scale. In our study site, heterogeneity in the ant-plant interactions among habitats is so prevalent that it emerges at community-level structural properties. High frequency of morphologically diverse and temporarily-active EFNs in all habitats suggests the relevance and seasonality of plant biotic defense provided by ants. The robust survey of ecological interactions and their biological/ecological correlates that we addressed provides insight of the interplay between adaptive-value traits and neutral effects in ecological networks. 
1 Title: Relative contribution of ecological and biological attributes in the fine-grain structure 2 of ant-plant networks

3

4 Authors: Cecilia Díaz-Castelazo ${ }^{1}$, Cristian Adrian Martínez-Adriano ${ }^{1,2}$, Wesley Dáttilo ${ }^{3}$, and $5 \quad$ Víctor Rico-Gray ${ }^{4}$

6

7

8 Affiliations: ${ }^{1}$ Red de Interacciones Multitróficas, Instituto de Ecología, A.C., Xalapa, Veracruz 9 91073, México. ${ }^{2}$ Facultad de Ciencias Forestales, Universidad Autónoma de Nuevo León, Linares,

10 Nuevo León, México. ${ }^{3}$ Red de Ecoetología, Instituto de Ecología, A.C. Xalapa, Veracruz 91073, 11 México. ${ }^{4}$ Instituto de Neuroetología, Universidad Veracruzana, Xalapa, Veracruz 91190, México.

12

13 Corresponding author: Cecilia Díaz-Castelazo. Carretera Antigua a Coatepec, No. 351, El Haya, 14 Xalapa, 91073, Veracruz, México.diazcastelazogm@gmail.com, cecilia.diaz@inecol.mx 


\section{Abstract}

Background. Ecological communities of interacting species analyzed as complex networks have shown that species dependence on their counterparts is more complex than expected at random. As for other potentially mutualistic interactions, ant-plant networks mediated by extrafloral nectar show a nested (asymmetric) structure with a core of generalist species dominating the interaction pattern. Proposed factors structuring ecological networks include encounter probability (e.g. species abundances and habitat heterogeneity), behavior, phylogeny, and body size. While the importance of underlying factors that influence the structure of ant-plant networks have been separately explored, the simultaneous contribution of several biological and ecological attributes inherent to the species, guild or habitat level has not been addressed.

Methods. For a tropical seasonal site we recorded (in 48 censuses) the frequency of pairwise antplant interactions mediated by extrafloral nectaries (EFN) on different habitats and studied the resultant network structure. We addressed for the first time the role of mechanistic versus neutral determinants at the 'fine-grain' structure (pairwise interactions) of ant-plant networks. We explore the simultaneous contribution of several attributes of plant and ant species (i.e. EFN abundance and distribution, ant head length, behavioral dominance and invasive status), and habitat attributes (i.e. vegetation structure) in prevailing interactions as well as in overall network topology (community).

Results. Our studied network was highly-nested and non-modular, with core species having high species strengths (higher strength values for ants than plants) and low specialization. Plants had higher dependences on ants than vice versa. We found that habitat heterogeneity in vegetation structure (open vs. shaded habitats) was the main factor explaining network and fine-grain structure, with no evidence of neutral (abundance) effects. 
39 Discussion. Core ant species are relevant to most plants species at the network showing 40 adaptations to nectar consumption and deterrent behavior. Thus larger ants interact with more plant 41 species which, together with higher dependence of plants on ants, suggests potential biotic defense

42 at a community scale. In our study site, heterogeneity in the ant-plant interactions among habitats

43 is so prevalent that it emerges at community-level structural properties. High frequency of 44 morphologically diverse and temporarily-active EFNs in all habitats suggests the relevance and 45 seasonality of plant biotic defense provided by ants. The robust survey of ecological interactions 46 and their biological/ecological correlates that we addressed provides insight of the interplay 47 between adaptive-value traits and neutral effects in ecological networks. 


\section{Introduction}

The interactions among species occurring at a community have been studied recently with a complex network perspective, where interacting species (i.e. plants and animals) are graphically represented as nodes and their trophic interactions as links (Bascompte et al., 2003). Such studies have paid important attention to network structure and its underlying factors, both for mutualistic or antagonistic interactions (Bascompte \& Jordano, 2007; Vázquez, Chacoff \& Cagnolo, 2009; Díaz-Castelazo et al., 2013; López-Carretero et al., 2014). Unraveling how interactions among species are structured in communities or ecosystems is crucial for understanding the ecological and evolutionary processes that support ecosystem function and diversity (Herrera \& Pellmyr, 2002). Furthermore, understanding the architecture of species relationships may help predict how ecosystems respond either to abiotic or human-derived changes (Bascompte, 2010).

Ecological network studies have shown that interactions among species are frequently asymmetric and species dependence on their counterparts is more complex than expected at random (Bascompte, Jordano \& Olesen, 2006; Guimarães et al., 2007). For networks of mutualistic interactions a nonrandom "nested" structure is frequently observed, where more specialist species tend to interact with specific subsets of those species interacting with the more generalist species (Almeida-Neto et al., 2008; Bascompte, 2010). Thus, nested structure implies that interactions occur asymmetrically in a group of generalist species that comprise most interactions in the network (network core) (Dáttilo et al., 2013b) and a group of specialist species that maintain few interactions mostly or exclusively with generalist species. Such as a nested architecture has been found to increase network robustness against loss of species (Memmott et al., 2004; Bascompte et al., 2006) and to maximize the number of coexisting species supported 
72 by these networks (Bastolla et al., 2009; Thébault \& Fontaine, 2010). A nested pattern of links in

73 mutualistic interaction networks could result from several ecological and evolutionary processes:

74 for instance, the complementarity and convergence of phenotypic traits between both sets of

75 interacting species (Thompson, 2005; Stang et al., 2006; Stang, 2007; Rezende, Bascompte \&

76 Jordano, 2007).

77 Another nonrandom structural pattern in ecological interaction networks is the

78

'modularity' or 'compartmentalization', which is characterized by a group of species interacting more strongly among themselves than with other species or subsets in the network (Bascompte, 2010). The modular pattern is more frequently observed for networks of antagonistic interactions (Cagnolo, Salvo \& Valladares, 2011). Like nestedness in mutualistic networks, modularity is thought to increase the persistence of species in antagonistic networks (Thébault \& Fontaine, 2010).

Proposed mechanisms affecting overall network structure are diverse, including habitat heterogeneity constraints (Pimm \& Lawton, 1980; López-Carretero et al., 2014), phylogeny (Rezende et al., 2007; Cagnolo, Salvo \& Valladares, 2011), body size (Cohen et al., 2005; Rezende, Bascompte \& Jordano, 2007; Chamberlain \& Holland, 2009;), encounter probability based on natural abundance of species (Vázquez, Chacoff \& Cagnolo, 2009; Blüthgen, 2010; Dáttilo et al., 2014a), and variation in spatiotemporal co-occurrence (Rico-Gray et al., 2012; Sánchez-Galván et al., 2012; Díaz-Castelazo et al., 2013; Junker et al., 2013; López-Carretero et al., 2014). Environmental changes may alter network structure and thus, favor evolutionary responses in opposing directions for different species (Guimarães, Jordano \& Thompson, 2011). The reorganization of network structure due to the indirect effects of coevolution, may explain 
94 why and how mutualisms persist amid the turnover of species and interactions through space and 95 time (Guimarães et al., 2017).

Several aggregate network properties such as nestedness, connectance (the proportion of realized interactions from all the ones possible given the number of species), and interaction asymmetry (i.e. asymmetry of dependence of plants on animals and vice versa) may also emerge due to properties inherent to communities (Jordano, Bascompte \& Olesen, 2006). These causes include the different abundances of species, community sampling biases (that affect the detectability of some interactions), and the spatio-temporal overlap of species (i.e. cooccurrence) (Vázquez et al., 2007, 2009; Blüthgen et al., 2008).

Although relative species abundance (Vázquez et al., 2009; Dáttilo et al., 2014a) and spatio-temporal overlap -considered as 'neutral' causes of network structure- could explain overall network structure, they fall short of predicting the frequency of pairwise interactions (Vázquez et al., 2009; Poisot, Stouffer \& Gravel, 2015). Indeed, the frequency of interactions occurring for any given pair of species within the network can vary significantly even if the overall network topology remains the same (Vázquez et al., 2005, 2007, 2009; Díaz-Castelazo et al., 2010; Dáttilo et al., 2014d; Sánchez-Galván et al., 2012).

The pattern and frequency of pairwise interactions is what we refer to here as, the 'finegrain' structure of the network, and is relevant since it could potentially demonstrate convergence or complementarity between species (Thomson, 2005; Guimarães, Jordano \& Thompson, 2011). Thus, a current challenge in ecological network studies is to infer which 114 processes are involved in the structuring the fine-scale patterns of interaction networks and how these may change over time (Ramos-Robles et al., 2016). Temporal changes in network structure and species composition may occur because of seasonal variability in weather (Rico-Gray et al., 
117 2012), food abundance (Carnicer, Jordano \& Melián, 2009; López-Carretero et al., 2014; Ramos-

118 Robles, Andresen \& Díaz-Castelazo et al., 2016), or plant traits (López-Carretero et al., 2016).

119 Progress in understanding the determinants of network patterns requires datasets with detailed

120 information of natural history such as spatial or temporal variation, morphological, behavioral, or

121 life-history traits, which explain interspecific differences observed between species in the

122 number and strength of interactions (Stang et al., 2006; Carnicer, Jordano \& Melian, 2009;

123 Junker et al., 2013; López-Carretero et al., 2016).

124 The study of ant-plant interactions at a community level has also been approached with the 125 theoretical/analytical framework of ecological networks (Chamberlain \& Holland, 2009; Díaz-

126 Castelazo et al., 2010; Dáttilo et al., 2013a; Fagundes et al., 2017). These ant-plant interactions

127 are mediated by several plant rewards for ants, such as extrafloral nectar, food bodies, fleshy

128 diaspores, or plant domatia (Rico-Gray \& Oliveira, 2007). At a community-level, plants

129 providing good-quality extrafloral nectar are highly attractive to ants and accumulate more

130 interactions with aggressive and territorial ant species (Blüthgen et al., 2004; Dáttilo et al.,

131 2014c), but more importantly, ant visits may result in a reduced herbivory damage (Oliveira et

132 al., 1999; Cuautle \& Rico-Gray, 2003; Fagundes et al., 2017). Plenty of variation in extrafloral

133 nectaries (EFN thereafter) attributes exist, including nectar volume, the amount of secreted

134 sugar, variable gland size and morphology, position of EFNs within plant organs, and differential

135 attractiveness to ant foragers (Koptur, 1992; Wäckers \& Bonifay, 2004, Díaz-Castelazo,

136 Chavarro-Rodríguez \& Rico-Gray, 2017). Many of these attributes show phenotypic plasticity or

137 context-dependency (Koptur, 1992; Rudgers, 2004; Wäckers \& Bonifay, 2004). In this context,

138 plant investment in nectar production and quality is a very important factor modifying the benefit 
139 received by plants through biotic defense, and fitness-related outcomes of the interaction

140 (Rudgers \& Gardner, 2004; Holland, Chamberlain \& Horn, 2009).

141 Ant-plant networks, including potentially mutualistic interactions ('potentially', because

142 benefits were assessed only for few interactions, see: Horvitz \& Schemske, 1984; Rico-Gray et

143 al., 1989; Cuautle, Rico-Gray \& Díaz-Castelazo, 2005; Rico-Gray \& Oliveira, 2007), have been

144 recently addressed focusing on their spatio-temporal variation (Díaz-Castelazo et al., 2010;

145 Sánchez-Galván et al., 2012; Díaz-Castelazo et al., 2013; Dáttilo et al., 2013b, 2014b) and/or

146 determining biotic/abiotic factors; among the latter, temperature and precipitation (Rico-Gray et

147 al., 2012), soil pH (Dáttilo et al., 2013a), and the temporal variation in the percentage of plants

148 with active extrafloral nectaries that mediate these interactions (Lange, Dáttilo \& Del-Claro,

149 2013), have important effects on the structure (i.e. nestedness, specialization) of ant-plant

150 networks mediated by extrafloral nectaries (EFNs).

151 Some studies have shown that variation in abundance of ants among different types of

152 vegetation, partially explains the network structure of mutualistic interactions, where abundant

153 ant species usually interact with more plant species (Dáttilo et al., 2014b). Similarly, the

154 abundance of plants-bearing extrafloral nectaries and plant size (Lange, Dáttilo \& Del-Claro,

155 2013) are important predictors of asymmetric (i.e. nested) interactions between plants and ants in

156 ant-plant networks. Ant species attributes may influence the structure in ant-plant networks,

157 include the social recruitment behavior of ants (Dáttilo et al. 2014b), as well as its invasive

158 potential (Ness \& Bronstein, 2004). Once a worker ant forager finds a profitable food source (i.e.

159 extrafloral nectar) it will (or not if it is a solitary forager) recruit nestmates using variable

160 strategies (Dornhaus \& Powell, 2010). These strategies includes group recruitment, tandem

161 running, mass recruitment by pheromone trail, trunk trails, team transport, etc. which are highly 
162 variable depending on ant species/genus or ecological context (Ness \& Bronstein, 2004; Lach

163 \&Hooper-Bui, 2010). Often, aggressive behavior of ants and numerical dominance are attributes

164 that influence the recruitment and competition abilities (Parr \& Gibb, 2010). Ant dominance

165 hierarchy determined by ant behavior also influences network structure since ant species found

166 in the central core of the network are frequently competitively superior (i.e. showing massive

167 recruitment and resource domination), compared with peripheral species with fewer interactions

168 (Dáttilo et al., 2014c). Furthermore, invasive ant species, given their opportunism, recruitment

169 behavior, and numeric dominance (Ness \& Bronstein, 2004; Lach \& Hooper-Bui, 2010), could

170 rapidly become important components of the core of ant-plant networks even if they do not

171 displace other ant species (Díaz-Castelazo et al., 2010; Falcão et al., 2017).

172 While the importance of abiotic/biotic factors have been separately explored for ant-plant

173 networks, the simultaneous relative contribution of biological attributes of species and ecological

174 and habitat level attributes (i.e. ecological correlates) in a facultative mutualistic ant-plant

175 network, is addressed here for the first time. Attributes of the species sets considered here are in

176 accordance with the foraging theory perspective required for a mechanistic understanding of

177 ecological networks (Ings et al., 2009). Our study system provides the opportunity to test

178 simultaneously the effect of several ecological and biological attributes of interacting species,

179 including morphology, behavior, and abundance as well as their inter-habitat (spatial) variation,

180 on the overall and 'fine-grain' structure of a quantitative mutualistic network. In particular we

181 addressed the following questions: 1) What is the network structure of this intensively-sampled

182 ant-plant community-mediated by extrafloral nectaries?; 2) Which is the "fine-grain" structure

183 emerging from the frequency (strength) of pairwise interactions?; 3) Which is the position of

184 species in the core/periphery structure of the network?; and 4) Which is the relative contribution 
185 of biological or ecological correlates (ant, plant, or habitat attributes) in rendering the "fine-

186 grain" and overall network structure?

187

188 Materials \& Methods

189 Study site and data collection

190 Field work was carried out in the Centro de Investigaciones Costeras La Mancha (CICOLMA), 191 located on the coast of the state of Veracruz, Mexico $\left(19^{\circ} 36^{\prime} \mathrm{N}, 9^{\circ} 22^{\prime} \mathrm{W}\right.$; elevation $\left.<100 \mathrm{~m}\right)$.

192 The climate is warm and sub-humid with rainy season between June and September, a total 193 annual precipitation is ca. $1500 \mathrm{~mm}$, and mean annual temperature is $22^{\circ}-26^{\circ} \mathrm{C}$ (Rico-Gray, 194 1993). The major vegetation types in the study area are tropical sub-deciduous forest, tropical 195 deciduous forest, coastal dune scrub, mangrove forest, freshwater marsh, and deciduous flood 196 forest (Castillo-Campos \& Travieso-Bello, 2006). Changes in the abundance of associations

197 between ants and plants bearing EFNs suggest that ant-plant interactions are strongly influenced 198 by climatic conditions as a result of marked seasonality (Díaz-Castelazo et al., 2004; Rico-Gray 199 \& Oliveira, 2007). Marked seasonality at the study site (rainy, dry, and cold-front seasons) 200 influences primary productivity and have a strong effect in animal-plant interactions (Rico-Gray, 201 1993; Díaz-Castelazo et al., 2004; Sánchez-Galván et al., 2012; López-Carretero et al., 2014;

202 Ramos-Robles, Andresen \& Díaz-Castelazo, 2016; Martínez-Adriano, 2017).

203 Biweekly observations were conducted between October 1998 and September 2000 (Rico204 Gray, 1993; Díaz-Castelazo et al., 2004), rendering an intensive sampling of 48 censuses along 205 six $1 \mathrm{~km}$ trails that sampled vegetation types representative of the plant communities in the study area: 1) pioneer dune vegetation (PDV), 2) coastal dune scrub (CDS), 3) tropical sub-deciduous

207 forest in young soil (TSF-Y), 4) tropical sub-deciduous forest in old soil (TSF-O), 5) tropical 
208 deciduous flood forest with wetland (TDF-W), and 6) mangrove forest ecotone (MFE)

209 (nomenclature as in Martínez-Adriano et al., 2016; derived from Castillo-Campos and Travieso-

210 Bello, 2006, following methods from Rico-Gray, 1993 and Díaz-Castelazo et al., 2004).

211 Vegetation associations differ in their structural complexity provided partly by arboreal plant

212 cover and contrasting physiognomies occur between "open" and "shaded" habitats. In

213 CICOLMA the first three habitats (PDV, CDS, and (TSF-Y) being included in the former

214 physiognomy and the other three habitats (TSF-O, TDF-W, and MFE) included in the latter

215 (Díaz-Castelazo et al., 2004; López-Carretero et al., 2014). Habitats 1, 2, and 3 are also different 216 from 4, 5, and 6 in their floristic similarity of flowering plants (Chao-Jaccard Similarity Index,

217 see Martínez-Adriano et al., 2016) and in the mean density of ants observed in honey baits

218 placed in (Díaz-Castelazo et al., 2004). In these six vegetation types we recorded all occurrences

219 of ants collecting liquids directly from all plants within each transect (ant-plant interactions). We

220 considered all plant life forms but only from those below $4 \mathrm{~m}$ in height, since no canopy

221 censuses were performed.

222

We also estimated the abundance of EFN-bearing plants through their line cover within each transect (please see Díaz-Castelazo et al., 2004 or Sánchez-Galván et al., 2012 for details).

On each visit at each transect we recorded: ant species, plant species, the plant organ where the extrafloral nectaries were located, and its distribution. Once an individual plant was marked as visited by ants, it was subsequently re-checked throughout the study. When doubt existed on the nectar source, EFN-secretion, we corroborated this with glucose reagent strips (Clinistix, Bayer).

We considered extrafloral nectar either produced by the surface of reproductive structures such as the spike, pedicel, bud, calyx, or fruit, or secreted by special structures on vegetative parts such as leaves, shoots, petioles, bracts, or stems. Ants were considered to be feeding on nectar 
231 when they were immobile, with mouthparts in contact with nectar secreting tissues for periods of

232 up to five minutes (Rico-Gray, 1993), although for some species, particularly when recruitment

233 of nestmates to the nectar source occurred, ant feeding was very evident and thus, recorded in

234 shorter time periods. Further information on the ant-plant interaction censuses showed at the

235 present study (including seasonal variations of species and attributes) is detailed in Díaz-

236 Castelazo et al. (2004) (Appendix 1, Figure 1).

237

Plant and ant attributes

239

Regarding the distribution of EFNs among plant organs, we used a general characterization

(see Díaz-Castelazo et al., 2005) differentiating the EFNs which are glands circumscribed to

particular plant organs or whorls (at specific or modular locations) from the ones dispersed among plant organs (i.e. secretory trichomes on leaves or surfaces of vegetative tissues). Díaz-

Castelazo et al. (2005) results raised the idea that gland distribution on plant organs could follow an aggregate (i.e. circumscribed) location against a widely dispersed location and this could result in distinct ant visitor arrays (Díaz-Castelazo et al., 2004). In a similar way that extrafloral nectar sources may differ from honeydew sources in their associated ant assemblages (Blüthgen \& Fiedler, 2004; Blüthgen et al., 2000). Circumscribed EFNs include: elevated glands, hollow glands (vascularized), transformed glands (vascularized), capitated trichomes (non-vascularized), and unicellular trichomes (non-vascularized). Disperse EFNs include: flattened glands, peltate trichomes, and scale-like trichomes (Díaz-Castelazo et al., 2005). distribution in vegetation associations with distinct habitat structure (open or shaded habitats), and (3) the distribution of the EFNs among plant organs (Table 1). Attributes for ants included 
254 the following: (1) behavioral dominance based in the classification of ant functional groups

255 proposed by Andersen (1995; 2000) in relation to plant life-forms, stress, and disturbance, (2)

256 head length, a robust estimator of body mass in ant species (Kaspari \& Weiser, 1999), and (3)

257 species status as invasive. The invasive status that we used was based in Holway et al. (2002),

258 with adjustments to include 'tramp' species status as well; invasive ants are those non-native ant

259 species which establish long-term populations and expand their range upon introduction to new

260 areas; while tramp ants are non-native transferred populations of ants closely tied with urban

261 areas and human activities (considered thus as "human commensals") (McGlynn, 1999; Lach \&

262 Hooper-Bui, 2010; Falcão et al., 2017); (Table 2).

263 We provide further detail on species attribute selection at the present study as follow.

264 Cover and distribution of EFN-bearing plant species (among habitats with different vegetation

265 structures) is an important factor influencing the richness and abundance of ant-plant interactions

266 (Díaz-Castelazo et al., 2004), interactions with other insects (López-Carretero et al., 2014), and

267 the spatio-temporal variations due to seasonality (Rico-Gray, 1993; Rico-Gray \& Oliveira, 2007;

268 Díaz-Castelazo et al., 2010). Similarly, the differential distribution of EFNs among plant organs

269 could favor different ant assemblages (Majer, 1993; Blüthgen \& Fiedler, 2004). This is essential

270 for the optimal defense of valuable reproductive plant organs compared to vegetative ones (Rico-

271 Gray, 1993; Wäckers \& Bonifay, 2004; Holland, Chamberlain \& Horn, 2009). Related to ant

272 attributes, behavioral dominance is a relevant feature in mutualistic ant-plant interactions given

273 that competitive species may exclude submissive ones (Andersen, 2000; Ness \& Bronstein,

274 2004; Lach \& Hooper-Bui, 2010; Dáttilo et al., 2014c). For example, head length has been

275 shown to be positively correlated with the number of plant species that each ant species interact

276 in ant-plant networks (knows as "degree"; Chamberlain \& Holland, 2009). Other relevant 
277 attribute that could affect the ant-plant interactions is the presence of invasive ant species since

278 many invasive species have behavior or foraging strategies that overcome their native

279 counterparts (Díaz-Castelazo et al., 2010) or disrupt the mutualistic interactions (Schultz \&

280 McGlynn 2000; Holway et al., 2002).

281

282 Data analysis

283 The ant-plant network analyzed here consists of a quantitative species-species matrix given by

284 the frequency of occurrence of each pairwise ant-plant interaction. Ecological and biological

285 attributes of the species were of different kinds and considered as highly important in modulating

286 the mutualistic interaction (Díaz-Castelazo et al., 2004; 2005).

287 The pairwise interaction matrix here considered is a highly informative sub-web taken

288 from Díaz-Castelazo et al. (2010), where we excluded those interactions that occurred at

289 considerably low frequencies (interactions recorded on less than three occasions from the whole

29048 censuses), in order to perform better multivariate analysis (NMDS), interpretation of biplot

291 ordinations, and adjustment of explanatory variables. This also reduced the probability of

292 considering a species with a single or very few interactions as a "specialist", when it was just a

293 very rare species and helped to avoid the overestimation of specialization, nestedness, and

294 strength asymmetry (Blüthgen et al., 2008).

295 For this informative network we analyzed nestedness (NODF) (Nestedness based on

296 Overlap and Decreasing Fill) (Almeida-Neto et al., 2008) using ANINHADO (Guimarães \&

297 Guimarães, 2006). This metric is robust to detect a nested pattern since it is less sensitive to

298 matrix size and shape than other measures such as nestedness derived from matrix Temperature

299 Almeida-Neto et al., 2008). Significance of the NODF value for our network was obtained with 
300 ANINHADO after comparing it with 1000 simulations using null model Ce (Guimarães \&

301 Guimarães, 2006), which corresponds to Null Model II of Bascompte et al. (2003). It assumes

302 that the probability of occurrence of an interaction is proportional to the observed number of

303 interactions of both plant and ant species (Bascompte et al., 2003; Dáttilo et al., 2013b). We then

304 estimated network topology or structural metrics (connectance, dependence asymmetry,

305 weighted nestedness, and niche overlap) using different indexes included in the function

306 "network-level” of the "bipartite" package (Dormann \& Gruber, 2009) in 'R' software ver. 3.5.1

307 (R Core Team, 2014).

Additionally, with the software MODULAR (Marquitti et al., 2013) we tested the existence

of a modular structure in the network with the modularity index (M). This index ranges $0-1$ and

was calculated with simulated annealing optimization approach (SA) (Guimerà \& Amaral,

2005). This metric was based on Barbers modularity metric which are recommended for bipartite

networks $\left(\mathrm{Q}_{\mathrm{B}}\right.$ (Barber, 2007). The statistical significance of modularity $(\mathrm{M})$ was calculated using

Monte Carlo tests with 1000 randomizations (Guimerà, Sales-Pardo \& Amaral, 2004). High

values of $\mathrm{M}$ indicate the occurrence of ants and plants in cohesive subgroups that generate

compartments or modules in which these species interact more closely than with the other species in the network (Olesen et al., 2007).

For calculation of the "fine-grain" structure of the network we used the "species-level"

318 function (Dorman, 2011) in the "bipartite" package. The metrics calculated for this objective

319 were "species strength" and d'. The first is defined as the sum of dependences of the plants

320 visited by this animal (or vice versa). Thus, species strength is a quantitative extension of the

321 metric "species degree" and provides information about the relevance of a species for their

322 interacting counterpart, being thus a meaningful measure of network complexity (Bascompte, 
323 Jordano \& Olesen, 2006). While, d' is the specialization of each species based on its

324 discrimination from random selection of partners (Blüthgen et al., 2008). Finally, we calculated

325 core-periphery structure of the network and its component species (i.e. which species constitute

326 the cohesive core are generalists, and which the low-degree species constitute the peripheral).

327 This metric was calculated with a function developed by Martínez-Adriano (2017) in R software

328 based on the formula proposed by Dáttilo, Guimarães \& Izzo (2013), where the species with

329 values equal or larger than 1 are considered as core components and species $<1$ are considered

330 peripheral.

331 In order to explore the among-species dissimilarities resulting in the interaction pattern of

332 the network, we generated the ordination of interaction frequencies with "Non-metric

333 Multidimensional Scaling (NMDS)" multivariate technique (Quinn \& Keough, 2002). This

334 method is specifically designed to graphically represent relationship between objects (i.e.

335 species/sites) in a multidimensional space provided by non-metric dissimilarities among objects

336 (Quinn \& Keough, 2002). NMDS is one of the most effective methods for the ordination of

337 ecological data and the identification of underlying gradients because it does not assume a linear

338 relationship among all variables (Quinn \& Keough, 2002). NMDS reduces the dimensionality of

339 a matrix among sample similarity coefficients, based on particular number of dimensions (Borg

340 \& Groenen, 1997). We chose the Bray-Curtis dissimilarity coefficient to construct the similarity

341 matrices because joint absences do not influence among sample similarity, and then we chose a

342 two-dimension configuration. The fit of an NMDS ordination, known as "stress", is determined

343 by how well the ordination preserved the actual sample dissimilarities, where values range from

344 zero to one (values of 0.2 and below are valid configurations to be interpreted). Because NMDS

345 analysis offers more than one solution, we carried out an iterative process to find the model with 
346 smallest stress value using the metaMDS function in "Vegan" package (Dixon, 2009) for R

347 software (R Core Team, 2014).

348 In order to explore the simultaneous relative contribution of several biological and

349 ecological species attributes and habitat level attributes on the interaction pattern (NMDS

350 ordination), we fitted those ecological/biological factors and vectors using the envfit function

351 from the "Vegan" package (Dixon, 2009) on R software (R Core Team, 2014). This function fit

352 the vectors (continuous variables) and factors (categorical variables) from the environmental

353 variables to the NMDS ordination, providing statistical significance by comparing our real model

354 of pairwise interactions with 1000 permutations of a given null model. The envfit function

355 provides a measure of correlation ( $\mathrm{r}$ ) and a significance value $(\mathrm{p})$ based on the probability that

3561000 random permutations of simulated (environmental) variables would have a better fit than

357 the real variables (Oksanen, 2009).

358 To test if the frequency of ants was different when foraging in the different EFN

359 morphological types, we performed a $\chi^{2}$ test. To test if between-group floristic similarity

360 (Sorensen's floristic similarity index, Češka, 1966) was higher than within group floristic

361 similarity we performed one-way ANOVA contrasting open and shaded habitats. With this

362 analysis we further confirm that open and shaded habitats differ in their vegetation structure and

363 in turn, provide differential biotic and abiotic conditions for inhabitant species, presumably

364 affecting the resultant network structure of ant-plant interactions. To explore if there was a

365 relation between ant head length and species degree in the network (the number of plant species

366 interacting with ants), we performed a Spearman rank correlation (Quinn \& Keough, 2002).

368 Results 
369 Network-level and fine-grain structure

370 Our ant-plant network involved 31 EFN-bearing plant species and 19 ant-forager species linked

371 by 1302 quantitative interactions (overall frequency of interactions) derived from 157 species

372 associations (links among species). The general topology shows a highly and significantly nested

373 network $\left(N O D F_{O b s}=49.13, N O D F_{(C e)}=34.93, P_{(C e)}<0.001\right)$. Although five modules were

374 detected in the modularity analysis (Barber's $\left.\mathrm{Q}_{\mathrm{B}}\right)$ the network was not significantly modular $(M=$

$3750.288, P=0.55$ ), thus no true compartments exist in the network (Fig 1). Network-level indexes

376 were: connectance $=0.267$, dependence asymmetry $=0.669$ (implying that plants depend more

377 on ants than the opposite), niche overlap among ant species $=0.223$, niche overlap among plant

378 species $=0.425$, and weighted nestedness $=0.554$ (implying that the network is still nested when

379 considering the frequency of pair-wise interactions). Four plant species and three ant species

380 constituted the central core of this network, the remaining species were peripheral. Plant core

381 species were: Cordia spinescens, Cedrela odorata, Callicarpa acuminata, and Crotalaria

382 incana, while ant core species were: Camponotus planatus, Camponotus mucronatus, and

383 Camponotus atriceps.

In terms of 'species strength', most plant species exhibited low strength values (below 1),

385

386

387

388

389

390

391 with higher strength values (around 2) which are Cordia spinescens, Cedrela odorata,

Callicarpa acuminata, and Turnera ulmifolia. These plant species are the most important EF

nectar sources for ant foragers at a community level. Species-level specialization values (d', considered as a measure of selectiveness) for plant species were also generally low (around 0.1), and only those plant species with few associated ant species (ant species with interaction patterns atypical or different from the rest) showed values above 0.3 , such as Ficus obtusifolia $\left(\mathrm{d}^{\prime}=0.43\right)$ 
392 and Senna occidentalis $\left(\mathrm{d}^{\prime}=0.37\right)$. In contrast with plants, some ant species had higher strength

393 values. Seven ant species had values above 1, and two core ant species, Camponotus planatus

394 and C. mucronatus, have strength values over 6, being thus very important visitors of EFN-

395 bearing plants; these ant species with high-strength values are relevant at a community level. On

396 the other hand, specialization (selectiveness) for ants was generally low (around 0.3, thus, higher

397 than plants), but few ant species had intermediate $\mathrm{d}^{\prime}$ values such as Tetramorium spinosum $\left(\mathrm{d}^{\prime}=\right.$

$3980.53)$ or Wasmannia auropunctata $\left(\mathrm{d}^{\prime}=0.43\right)$ not only because they interact with few plant

399 species but with plants visited by few ant species.

400

401

402

\section{Relative contribution of attributes to the assemblage of pair-wise interactions}

Attributes of species are summarized as follows: plant species with circumscribed nectaries 403

(Table 1) produced larger mean nectar volumes $(2.06 \mu 1)$, than those plants with dispersed

404

nectaries $(0.53 \mu 1)$. However, the number of active glands in a plant individual may be higher for 405

dispersed nectaries, since these glands are structurally simpler than those of circumscribed

406

nectaries. The frequency of ants foraging on the different EFN morphological types (Díaz-

407 Castelazo et al. 2005; Díaz-Castelazo, Chavarro-Rodríguez \& Rico-Gray, 2017) were different

$\left(\chi^{2}=1091.7, P<0.01\right)$. Moreover, the range of total associated ant species visiting plants

considered to have each type of nectary is different among EFN distribution types. The range of and 23 ant species for disperse nectaries.

We considered the two main vegetation structural associations (“open" vs. "shaded 
415 each group (36.06 and 41.28 for open and shaded habitats, respectively). See Methods for

416 information on the vegetation associations, either of "open or shaded habitats".

417 The stress value of the multivariate Non-Metric Multidimensional Scaling (NMDS)

418 obtained at the fourth run of the iterative process was the lowest $(0.17)$, and suggests that the

419 NMDS two-dimensional solution of the ordination suitably represented ant-plant assemblage

420 dissimilarity. This configuration also had very low residuals ( $\max$ res $=0.0004)$ indicating a

421 good concordance between the calculated dissimilarities and the distances among objects. In Fig.

422 2, axis NMDS1 is related to the contribution or importance of plant species to the ant forager

423 community. Those plant species that are ordered at the extremes of axis NMDS1, either with low

424 (negative) or higher (positive) values for component NMDS1, have low species strength values;

425 thus, these plant species have 'atypical' interaction patterns (and occupy in Fig. 1, the lowest or

426 basal position within the network). In contrast, at axis 1 of NMDS, those plant species

427 aggregated near zero are those plant species with the highest species strength or relevance for the 428 associated ant community. For ants, no generic or grouping trends are apparent. Axis NMDS2 429 divides plant species according to the main habitats where they occur. Starting from the upper 430 part of the ordination and ending at the lower part, we see an arrangement of the plant species 431 according to a 'humidity' gradient of habitats; first we see plants of shaded habitats with modest

432 light incidence and higher humidity and at the lower part of the biplot along axis 2 we see the 433 plants of the drier habitats. The higher values for NMDS2 show (in decreasing order) plants (and 434 associated ants) from the MFE, followed TSF-W, and TSF-O. At the bottom of the bi-plot, the 435 plants and ants occurring mostly in open vegetation types with high light incidence: from zero to 436 the lowest values of NMDS2, the interacting species are arranged through TSF-Y, CDS, and 437 PDV. 
439 showed that vegetation associations with differential structure (open vs. shaded habitats) were

440 the variables that determined the variation in the frequency of ant-plant pairwise interactions-

441 mediated by EFNs $\left(r^{2}=0.24, P=0.005\right)$. Two contrasting groups were formed along NMDS2,

442 which were plant species (and their associated ant forager species) located either in open or 443 shaded habitats (Fig. 2). Neither the distribution of EFNs on plant organs, nor the abundance of 444 extrafloral-nectary bearing plants at each vegetation type, had a significant contribution to the 445 variation in the observed ant-plant association patterns.

446 None of the variables of ant species (behavioral dominance, invasive status or head length)

447 showed in Table 2, explain the network's fine-grained structure. However, we found a significant 448 positive correlation between ant head length and species degree (the number of plant species 449 interacting with ants) (Spearman rank correlation, $\mathrm{rs}=0.565, P<0.05)$. A trend at the NMDS 450 ordination is that the invasive (tramp) ant species in our study (Solenopsis geminata, Wasmannia 451 auropunctata, Tetramorium spinosum, and Paratrechina longicornis) separate from the rest of 452 ant species at the interaction display. However, when all ant attributes are simultaneously 453 considered, they do not provide significant contribution to the variation in the observed ant-plant 454 association pattern.

\section{Discussion}

\section{Network-level and fine-grain network structure}

Our studied network, comprising 31 plant and 19 ant species attached by 157 interaction 
461 structure, as the non-modular structure that occurs commonly in theoretical mutualistic networks,

462 especially for facultative non-symbiotic interactions (Guimarães et al., 2007). Few species with

463 very high interaction frequencies exists within our network (eight plant and four ant species),

464 referred as 'super-generalists'. Super-generalist species are fundamental components for the

465 maintenance of convergence at the community level within highly diversified mutualistic

466 assemblages (Guimarães, Jordano \& Thompson, 2011). In our study, super-generalist species

467 may favor trait convergence. That is, core ant species belong to the same functional group

468 (Subordinate Camponotini) and share adaptations for foraging on plant-derived liquids resources

469 such as extrafloral nectar (Davidson, Cook \& Snelling, 2004). Similarly, core plants species

470 show mostly "disperse" EFNs, a gland distribution that may favor a more diverse array of

471 associated ant visitors.

472 In our study system, the fact that the plant 'guild' shows higher dependence asymmetry

473 values than ants, implying that the studied community plants 'depend' more on ants as a guild

474 than the opposite. It is also reinforced by the higher species strength values of ants than those

475 given for plants. This asymmetry could reflect a higher temporal turnover of plants at the

476 network - perhaps caused by seasonality or disturbance versus higher ant resilience- probably

477 derived from facultative foraging of ants. Three of four plant species constituting the core of this

478 network had high strength values (Cordia spinescens, Cedrela odorata, and Callicarpa

479 acuminata); these results suggest that the most connected plant species are important resources

480 for the ants at the community level. However, the relative importance of specific plant species

481 for this ant community do not seem related to specific biological attributes or neutral effects

482 since neither mean nectar volumes secreted by each plant species (Díaz-Castelazo et al., 2005;

483 Díaz-Castelazo, Chavarro-Rodríguez \& Rico-Gray, 2017), nor gland distribution or plant 
484 abundance explained core composition and species strength of plant species. Instead, this pattern

485 seems to emerge from degree and interaction frequencies, possibly driven by other higher-scale

486 factors (i.e. habitat structure, species co-occurrence, abiotic variables, etc.).

487 The rest of plant species showed very low species strength values, having thus a modest

488 relevance for the ant community. Species-level specialization values (d') for plant species were

489 also generally low (around 0.1) and only those plant species with few associated ant species

490 (with an atypical interaction pattern) exhibited values above 0.3 . These findings are in

491 accordance with the generalized, highly nested structure of this network. For potentially

492 mutualistic networks (such as this) and for facultative ant-plant interactions (such as those

493 mediated by extrafloral nectar), low specialization or selectiveness for each species (and the

494 whole network) is the general trend (Bascompte et al., 2003; Vázquez \& Aizen, 2004; Díaz-

495 Castelazo et al., 2010).

496 In contrast with plants (which have lowest species strength values), the ant species that

497 constitute the core of this network (Camponotus planatus, Camponotus mucronatus, and

498 Camponotus atriceps) had species strength values above 1. Camponotus planatus and $C$.

499 mucronatus have strength values above 6, being thus remarkably important visitors of EFN-

500 bearing plants. Species belonging to this genus are frequent visitors of EFNs (Díaz-Castelazo et

501 al., 2004; Díaz-Castelazo et al., 2013) and solitary leaf foragers that cover high foliar areas.

502 Camponotus species have high ability to rapidly take up nectar given their proventricular

503 adaptations that allow passive damming of sugary liquids, large crop capacities, and seeping

504 canals to nourish the midgut (Davidson, Cook \& Snelling, 2004). Thus, this group of ants is

505 highly adapted to forage on nectar and sugary liquids. It is understandable that at the present

506 study Camponotus species have high degree, high strength values, and low levels of 
507 specialization or selectiveness (d'). Given that these ants are physiologically adapted to forage in

508 all available extrafloral nectar sources and not having any trophic restriction, they tend to be

509 generalist visitors of EFN-bearing plants. Although some other ecological aspects -such as

510 competition ability of other ant species and resource attractiveness (Dáttilo et al., 2014c)- may

511 differentiate visitation pattern of these core ant species. In our studied community core ant

512 species are relevant to most plants species at the network and the plant species depend more of

513 ant species than the opposite. Adaptations to nectar consumption and deterrent behavior of core

514 ants (as well as their high interaction frequency), suggest that these species may provide

515 potential biotic defense at a community scale; this do not exclude the possibility that many other

516 ant species provide biotic defense at smaller scales or for particular plant species.

517

518 Relative contributions of the attributes to the assemblage of pairwise interactions

519 Major vegetation associations grouped according to habitat structure were the only factors that 520 explained variations in pair-wise interactions or fine-grain structure of the network. Open and

521 shaded habitats at the study site seem to differ structurally in vegetation and on their abiotic

522 conditions, which may in turn be important determinants for insect-plant interactions (López-

523 Carretero et al., 2014). Although, some studies have discussed the possible effects of abiotic

524 variables on ant-plant networks (Díaz-Castelazo et al., 2010; Rico-Gray \& Oliveira, 2007

525 (references therein); Rico-Gray et al., 2012, Sánchez-Galván et al., 2012), our study is the only

526 one addressing habitat abiotic effects jointly with species-level biological attributes and neutral

527 explanations (i.e. abundance) in a quantitative ant-plant network.

528 A mechanistic explanation for the differential ant-plant association pattern between open

529 and shaded habitats (suggesting habitat complexity effects; Dáttilo et al., 2013b), could include 
530 light incidence (under light conditions, jasmonic acid-induced EFN secretion is higher than in

531 dark conditions), 'attractiveness' or nutritional value of extrafloral nectar secreted by 'light

532 demanding' plant species compared to 'shade tolerant' ones, and the physiological tolerance of

533 ants to high temperatures (Radhika et al., 2010). Increased photosynthetic activity of plants in

534 open light-rich habitats could result in higher carbohydrate availability in extrafloral nectar and

535 thus increased attractiveness to ants (Radhika et al., 2010), or a higher density of EFN-bearing

536 plant life forms (such as vines). EFN-bearing plants growing in sunlight obtain a measurable

537 benefit from ant visitation, whereas the same plant species growing under shaded conditions has

538 no such a benefit (e.g., Bentley, 1976; Frank \& Fonseca, 2005). For some plant species size of

539 EFNs and nectar secretion are higher under intense light conditions compared to low light

540 conditions (Yamawo \& Hada, 2010) and a similar trend is found for the ant abundance foraging

541 on these glands (Rudgers \& Gardener 2004, Yamawo \& Hada, 2010). This effect of site

542 conditions on EFN abundance and secretory activity could also exist in our study system since

543 vegetation types with canopy cover (shaded) versus open habitats do sustain different species

544 abundances, floristic similarities (Díaz-Castelazo et al., 2004), and patterns of specific insect-

545 plant interactions (López-Carretero et al., 2014).

546 Among-habitat heterogeneity in vegetation structure (as well as seasonality) in our study

547 site is so prevalent (having a strong effect in animal-plant interactions as seen in Rico-Gray,

548 1993; Díaz-Castelazo et al., 2004; Sánchez-Galván et al., 2012; López-Carretero et al., 2014; and

549 Ramos-Robles, Andresen \& Díaz-Castelazo, 2016). This is clearly detected in the ant-plant

550 interaction pattern, in contrast to other studies where vegetation structure differences are not so

551 outstanding as have an effect in other ant-plant networks (Dáttilo et al., 2013b). Further evidence

552 of among-habitat heterogeneity translating to ant-plant network structure is provided in the 
553 present study by the multivariate analysis. In this analysis one of the components explaining the

554 variance in the lack of independence among ant and plant species (NMDS2) displays habitats

555 following a decreasing humidity gradient, from MFE, followed by TSF-W and TSF-O, TSF-Y,

556 CDS and PDV. Indeed, open habitats at the study site, such as coastal dune scrub (CDS) and

557 pioneer dune vegetation (PDV) have the most extreme temperatures, solar radiation (Moreno-

558 Casasola, 1982; Moreno-Casasola \& Travieso-Bello, 2006), and are exposed to continual

559 disturbance (López-Carretero et al., 2014) like sand movement, strong winds, and abrasion

560 (Pérez-Maqueo, 1995).

561 Our results showed that no neutral effects derived from variation in species abundances

562 are structuring the studied ant-plant network. Abundance of EFN-bearing plant species was

563 considered in our analysis but rendered no significant contribution to explain the frequency of

564 pairwise ant-plant interactions. Similar results were found for another ecological network at the

565 same study site such as a plant-herbivore network (López-Carretero et al. 2016), where network

566 parameters were not influenced by plant cover (abundance) but by biological and seasonality

567 aspects. In our study, although ant abundance was not included, we know from robust estimates

568 of ant density (honey baits) at the same periods of time and vegetation types that average ant

569 density is higher in open habitats than in shaded ones (Díaz-Castelazo et al., 2004). In other

570 studies of ant-plant interactions, the abundance of interacting species partially explain some

571 features of network structure (Vázquez et al. 2007; Dáttilo et al., 2014a). However, Dáttilo et al.

572 (2014a) show that although more abundant ant species interact with more plant species with

573 EFNs, information on the difference in abundance among interacting species was insufficient to

574 explain ant-plant network organization. That is, nestedness was higher in networks of ants and

575 plants with EFNs than that observed in networks of ants and plants without EFNs. Thus, the 
576 differences in nestedness, connectance, and heterogeneity of interactions remained after

577 controlling for the effects of species richness structure.

578 Other potentially mutualistic networks have shown that species abundance or temporal

579 overlap is far from accurately predicting the frequency of pair-wise interactions (Jordano,

580 Bascompte \& Olesen, 2006; Vázquez et al., 2009). Poisot, Stouffer \& Gravel (2015) outline

581 several direct (abundance-based and trait-based) and indirect (biotic modifiers and indirect

582 effects of co-occurrence) effects to account for variation in interactions occurrence. Given that

583 perspective, at the sampling intensity and duration of our ant-plant interaction survey (this reflect

584 temporal and spatial variation; see Díaz-Castelazo et al. 2004), neither the abundance-based nor

585 the trait-based modifiers seems to be enough relevant to explain the variation in pairwise ant-

586 plant interactions, even if at other scales ant abundance could partially explain an overall

587 network pattern (Dáttilo et al., 2014a). In contrast, an indirect effect given by habitat structure

588 (biotic modifiers through co-occurrence, sensu Poisot, Stouffer \& Gravel, 2015) more thoroughly

589 explains the quantitative interaction pattern at the present study.

590 The fact that neither the distribution of EFNs on plant organs nor the abundance of

591 extrafloral-nectary bearing plants at each vegetation type had a significant contribution to the

592 variation in the observed ant-plant association patterns, does not rule out its potential effect on

593 ant foraging patterns in other ecosystems or spatial scales (Dáttilo et al. 2013a, 2014b). At our

594 study site, besides the overwhelming evidence of seasonality and habitat heterogeneity (we did

595 find an effect of habitat structure in ant-plant interactions within the network), the high

596 occurrence frequency and seasonal activity of morphologically diverse EFNs at vegetation

597 associations (Díaz-Castelazo et al., 2004; Díaz-Castelazo et al., 2005) suggests a temporal

598 variation in benefits provided by ant visitors to EFN-bearing plants. Indeed, at the studied 
599 habitats, several plant species receive anti-herbivory defense from ants foraging on EFNs

600 (Oliveira et al. 1999; Cuautle and Rico-Gray 2003; Chavarro-Rodríguez et al. 2013). There is

601 also evidence that the frequency of ants foraging on different EFN morphologies and

602 distributions among plant organs differs (Díaz-Castelazo, Chavarro-Rodríguez \& Rico-Gray,

603 2017). Other anti-herbivory plant defenses of plant species at the study site have shown spatial

604 and temporal variation (López-Carretero et al., 2016; López-Carretero et al., 2018). Thus,

605 information on the contribution to plant fitness of the EFN occurring among plant organs (and

606 their temporal activity patterns) could shed light on the optimal defense-value of EFN resources

607 as an indirect defense (Holland, Chamberlain \& Horn, 2009) mediated by ants, an issue not yet

608 explored at a community-level.

$609 \quad$ For ant variables, although ant size (head length) was not a significant factor explaining

610 frequency of pairwise interactions, it was important in explaining other attributes such as species

611 degree within our mutualistic network. This may occur because competition among ant species

612 foraging at EFNs could vary with ant body size, size of ants contributing thus to the species

613 degree values (Chamberlain \& Holland 2009). Larger ant species can forage over a greater area

614 than small species, and thus interact with more plant species; in addition, it has been shown that

615 recruitment of ant foragers to a resource is negatively correlated with ant body size (LeBrun,

616 2005). That is, while ant body size increases, the number of recruiting foragers decreases, which

617 can lead to a body size-driven competition hierarchy in which larger ant species visit more plant

618 species.

619 Overall, behavioral dominance as a factor was not significant to explain variations in the

620 frequency of pair-wise interactions, possibly due to the spectrum of factors considered

621 simultaneously within the analysis since the EFNs considered here include both disperse EFNs 
622 and circumscribed EFNs that could provide resources for both dominant and non-competitive ant

623 species. However, ant invasive/tramp species in the study site (Solenopsis geminata, Wasmannia

624 auropunctata, Tetramorium spinosum, and Paratrechina longicornis) seem to have a slightly

625 different pattern of interaction from the other species (separate from the rest of ant species in the

626 interaction display), probably due to their ability to access new habitats or food resources (Ness

$627 \&$ Bronstein, 2004; Lach \& Hooper-Bui, 2010). This makes sense in such a human-altered

628 ecosystem as La Mancha, that seems to rapidly reflect ant invasions. At smaller time-scales, in

629 the same study site ant invasiveness does not alter the core structure of the network (Falcão et al.,

630 2017), despite of other possible functional effects in the community that are just about to be

631 explored.

632

633 Conclusions

634 Our extrafloral-nectary mediated ant-plant network was highly nested, non-modular, 635 showed high species strength for core species, low specialization or selectiveness, and higher 636 dependence of plants on ants. These results in accordance to a facultative mutualism scenario, 637 mainly considering that the core ant species in this interaction network are known as good plant638 defenders in general (Oliveira et al., 1999; Cuautle \& Rico-Gray, 2003; Dáttilo et al., 2014c).

639 When simultaneously exploring plants, ants, and habitat attributes on a network-level and 640 fine-grain structure, the only factor that significantly affects the pair-wise interactions is habitat 641 heterogeneity in the vegetation structure (and distribution of EFN-bearing plant species). At our 642 study site this heterogeneity is so strong that is clearly detected in the ant-plant interaction 643 network patterns, both in network topology and in the fine-grain network structure provided by 
644 the frequency of pair-wise interactions. This provides further evidence of abiotic factor influence 645 on facultative mutualism and biotic plant defense.

646 Habitat heterogeneity in vegetation structure and distribution of EFN-bearing plant 647 species suggest variability in plant strategies for biotic anti-herbivory defense. In our study the 648 plant species in shaded habitats have disperse EFNs more frequently, while plants at open 649 habitats have circumscribed EFNs with most frequency. The latter EFNs are more structurally 650 complex glands (i.e. elevated or pit nectaries) and are more effectively protected against nectar 651 evaporation (Koptur, 1992; Nepi, 2007), which is important at these open, insolated, high652 temperature sites.

Non-neutral effects were detected in the ant-plant interacting community since EFN-

654 655

656 657 658 659

660

661

662

663

664

665 bearing plant abundance per se had no effects in the ant-plant interaction pattern. As we showed before, more ecological/biological factors, such as habitat/vegetation structure, could affect network structure. Thus, possible convergence effects of interacting species in open vs. shaded habitats could be occurring presided by supergeneralist species and consequently, the possibility of cascading coevolutionary events taking place. This may deserve further study considering ecological/abiotic and coevolutionary contexts for mutualistic interaction networks (Guimarães et al. 2017).

\section{Acknowledgements}

We wish to acknowledge Mariana Cuautle, Rosa Linda Robles, and Gloria Castelazo for their assistance during fieldwork. Fernando Ortega helped with the characterization of extrafloral nectaries. Paulo R. Guimarães and Pedro Jordano made suggestions that improved this 
666 manuscript at early stages. Exclusively CDC thanks for the achievement of this study to God

667 Almighty for the gifts of life, of Christ and his unchanging love and grace.

668

669 References

670 Almeida-Neto M, Guimarães P, Guimarães PRJr, Loyola RD, Ulrich W. 2008. A consistent

671 metric for nestedness analysis in ecological systems: reconciling concept and measurement.

672 Oikos 117:1227-1239. DOI:10.1111/j.2008.0030-1299.16644.x

673 Andersen AN. 1995. A classification of Australian ant communities, based on functional groups

674 which parallel plant life-forms in relation to stress and disturbance. Journal of Biogeography

$675 \quad 22: 15-29$.

676 Andersen AN. 2000. A global ecology of rainforest ants: functional groups in relation to

677 environmental stress and disturbance. In: Agosti D, Majer JD, Alonso LE, Schultz TR, eds.

678 Ants: standard methods for measuring and monitoring biodiversity. . Washington:

679 Smithsonian Institution Press, 25-34.

680 Barber MJ. 2007. Modularity and community detection in bipartite networks. Physical Review E.

$681 \quad 76: 066102$.

682 Bascompte J, Jordano P, Melián CJ, Olesen JM. 2003. The nested assembly of plant-animal

683 mutualistic networks. Proceedings of the National Academy of Sciences of the United States

684 of America 100:9383-9387. DOI:10.1073/pnas.1633576100.

685 Bascompte J, Jordano P, Olesen JM. 2006. Asymmetric coevolutionary networks facilitate

686 biodiversity maintenance. Science 312:431-433.

687 Bascompte J. 2009. Disentangling the web of life. Science 325:416-419.

688 Bascompte J. 2010. Structure and dynamics of ecological networks. Science 329:765-766. 
689 Bastolla U, Fortuna MA, Pascual-García A, Ferrera A, Luque B, Bascompte J. 2009. The 690 architecture of mutualistic networks minimizes competition and increases biodiversity. $691 \quad$ Nature 458(7241):1018.

692 Bentley BL. 1976. Plants bearing extrafloral nectaries and the associated ant community: 693

Blüthgen N, Verhaagh M, Goitía W, Jaffé K, Morawetz W, Barthlott W. 2000. How plants shape Interhabitat differences in the reduction of herbivore damage. Ecology 57:815-820.

696 the ant community in the Amazonian rainforest canopy: the key role of extrafloral nectaries

697

698

699

700

701

702

703

704

705

706

707

708

709

710

711 and homopteran honeydew. Oecologia 125:229-240.

Blüthgen N, Fiedler K. 2004. Competition for composition: lessons from nectar-feeding ant communities. Ecology 85:1479-1485.

Blüthgen N, Fründ J, Vázquez DP, Menzel F. 2008. What do interaction network metrics tell us about specialization and biological traits? Ecology 89:3387-3399.

Blüthgen N. 2010. Why network analysis is often disconnected from community ecology: A critique and an ecologist's guide. Basic and Applied Ecology 11:85-195.

Borg I, Groenen P. 1997. Modern Multidimensional Scaling. Springer, New York.

Cagnolo L, Salvo A, Valladares G. 2011. Network topology: patterns and mechanisms in plant-herbivore and host-parasitoid food webs. Journal of Animal Ecology 80(2): 342-351.

Carnicer J, Jordano P, Melián CJ. 2009. The temporal dynamics of resource use by frugivorous birds: a network approach. Ecology 90:1958-1970.

Castillo-Campos G, Travieso-Bello AC. 2006. La flora. In: Moreno-Casasola ed. Entornos Veracruzanos: la costa de La Mancha. Instituto de Ecología, A.C., México. Instituto de Ecología, A.C., México.

Češka, A. (1966). Estimation of the mean floristic similarity between and within sets of 
712 vegetational relevés. Folia Geobotanica et Phytotaxonomica, 1(2), 93-100.

713 Chamberlain SA, Holland JN 2009. Body size predicts degree in ant-plant mutualistic networks.

$714 \quad$ Functional Ecology 23: 196-202.

715 Chavarro-Rodríguez N, Díaz-Castelazo C, Rico-Gray V. 2013. Characterization and functional 716 ecology of the extrafloral nectar of Cedrela odorata in contrasting growth environmets in 717 central Veracruz, Mexico. Botany 91, 695-701.

718 Cohen JE, Jonsson T, Müller CB, Godfray HCJ, Savage VM. 2005. Body sizes of hosts and 719 parasitoids in individual feeding relationships. Proceedings of the National Academy of $720 \quad$ Sciences of the United States of America 102:684-689.

721 Cuautle M, Rico-Gray V. 2003. The effect of wasps and ants on the reproductive success of the 722 extrafloral nectaried plant Turnera ulmifolia L. Turneraceae. Functional Ecology 17:417$723 \quad 423$.

724 Cuautle M, Rico-Gray V, Díaz-Castelazo C. 2005. Effects of ant behaviour and presence of 725 extrafloral nectaries on seed dispersal of the Neotropical myrmecochore Turnera ulmifolia

Dáttilo W, Rico-Gray V, Rodrigues DSJ, Izzo T. 2013a. Soil and vegetation features determine Oikos 122:1643-1648.

Dáttilo W, Sánchez-Galván I, Lange D, Del-Claro K, Rico-Gray V. 2014d. Importance of interaction frequency in analysis of ant-plant networks in tropical environments. Journal of Tropical Ecology 30:165-168. 
735

736

737

738

739

740

741

742

743

744

745

746

747

748

749

750

751

752

753

754

755

756

757

Dáttilo W, Marquitti FMD, Guimarães PR, Izzo TJ. 2014a. The structure of ant-plant ecological networks: is abundance enough? Ecology 95:475-485.

Dáttilo W, Fagundes R, Gurka CAQ, Silva MSA, Vieira MCL, Izzo TJ, Díaz-Castelazo C, DelClaro K, Rico-Gray V. 2014b. Individual-based ant-plant networks: diurnal-nocturnal structure and species-area relationship. PLoS ONE 9:e99838.

Dáttilo W, Díaz-Castelazo C, Rico-Gray V. 2014c. Ant dominance hierarchy determines the nested pattern in ant-plant networks. Biological Journal of the Linnean Society 113:405414.

Davidson DW, Cook SC, Snelling RR. 2004. Liquid-feeding performances of ants (Formicidae): ecological and evolutionary implications. Oecologia 139:255-266.

Díaz-Castelazo C, Rico-Gray V, Oliveira PS, Cuautle M. 2004. Extrafloral nectary-mediated ant-plant interactions in the coastal vegetation of Veracruz, Mexico: richness, occurrence, seasonality and ant foraging patterns. Ecoscience 11:472-481.

Díaz-Castelazo C, Rico-Gray V, Ortega F, Ángeles G. 2005. Morphological and secretory characterization of extrafloral nectaries in plants of coastal Veracruz, Mexico. Annals of Botany 96:1175-1189.

Díaz-Castelazo C, Guimarães PR, Jordano P, Thompson JN, Marquis RJ, Rico-Gray V. 2010. Changes of a mutualistic network over time: reanalysis over a 10-year period. Ecology $91: 793-801$.

Díaz-Castelazo C, Sánchez-Galván IR, Guimarães PR, Raimundo RLG, Rico-Gray V. 2013. Long-term temporal variation in the organization of an ant-plant network. Annals of Botany 111:1285-1293.

Díaz-Castelazo C, Chavarro-Rodríguez N, Rico-Gray V. 2017. Interhabitat variation in the 
758

759

760

761

762

763

764

765

766

767

768

769

770

771

772

773

774

775

776

777

778

779

780

ecology of extrafloral nectar production and associated ant assemblages in Mexican landscapes. In: Oliveira PS, Koptur S. Ant-Plant Interactions: Impacts of Humans on Terrestrial Ecosystems. Cambridge University Press. Pp. 179-199.

Dixon P. 2009. VEGAN, a package of R functions for community ecology. Journal of Vegetation Science 14:927-930. DOI:10.1111/j.1654-1103.2003.tb02228.x.

Dormann CF, Fruend J, Blüthgen N, Gruber B. 2009. Indices, graphs and null models: analyzing bipartite ecological networks. The Open Ecology Journal 2:7-24.

Dormann CF, Gruber B. 2009. Package 'Bipartite': visualizing bipartite networks and calculating some ecological indices. R statistical software. 'R group'.

Dormann CF. 2011. How to be a specialist? quantifying specialization in pollination networks. Network Biology 1:1-20. URL:http://www.iaees.org/publications/journals/nb/articles/20111(1)/How-to-be-a-specialist.pdf

Dornhaus A, Powell S. 2010. Foraging and defence strategies in ants. In: Lach L, Parr CL, Abbott KL eds. Ant ecology, Oxford, UK: Oxford University Press, 210-230.

Falcão JC, Dáttilo W, Díaz-Castelazo C, Rico-Gray V. 2017. Assessing the impacts of tramp and invasive species on the structure and dynamic of ant-plant interaction networks. Biological Conservation 209:517-523.

Frank MK, Fonseca CR. 2005. Abiotic factors and the conditional outcome of an ant-plant mutualism. Ecology 86:2117-2126.

Guimarães PR, Guimarães P. 2006. Improving the analyses of nestedness for large sets of matrices. Environmental Modelling and Software 21:1512-1513.

Guimarães PR, Rico-Gray V, Oliveira PS, Izzo TJ, dos Reis SF, Thompson JN. 2007. Interaction intimacy affects structure and coevolutionary dynamics in mutualistic networks. Current 
Biology 17:1797-1803.

782 Guimarães PR, Jordano P, Thompson JN. 2011. Evolution and coevolution in mutualistic networks. Ecology Letters 14: 877-885.

784

785

786

787

788

789

790

791

792

793

794

795

796

797

798

799

800

801

802

Guimerà R, Amaral LAN. 2005. Functional cartography of complex metabolic networks. Nature 433:895-900.

Herrera CM, Pellmyr O. 2009. Plant animal interactions: an evolutionary approach. John Wiley \& Sons.

Holland JN, Chamberlain SA, Horn KC. 2009. Optimal defence theory predicts investment in extrafloral nectar resources in an ant-plant mutualism. Journal of Ecology 97: 89-96.

Holway DA, Lach L, Suarez AV, Tsutsui ND, Case1 TJ. 2002. The causes and consequences of ant invasions. Annual Review of Ecology and Systematics 33:181-233.

Horvitz CC, Schemske DW. 1984. Effects of ants and an ant tended herbivore on seed production of a Neotropical herb. Ecology 65:1369-1378.

Ings TC, Montoya JM, Bascompte J, Blüthgen N, Brown L, Dormann CF, Edwards F, Figueroa D, Jacob U, Jones JI, Lauridsen RB, Ledger ME, Lewis HM, Olesen JM, van Veen FJF, Warren PH, Woodward G. 2009. Ecological networks-beyond food webs. Journal of Animal Ecology 78:253-269.

Jordano P, Bascompte J, Olesen JM. 2003. Invariant properties in coevolutionary networks of 
803 plant-animal interactions. Ecology Letters 6:69-81.

804 Jordano P, Bascompte J, Olesen JM. 2006. Ecological consequences of complex topology and 805 nested structure in pollination webs. In: Waser N.W. \& Ollerton J. Plant-Pollinator 806 Interactions: From Specialization to Generalization. The University of Chicago Press. 807 Junker RR, Blüthgen N, Brehm T, Binkenstein J, Paulus J, Martin Schaefer H, Stang M. 2013. 808 Specialization on traits as basis for the niche-breadth of flower visitors and as structuring 809 mechanism of ecological networks. Functional Ecology 27(2):329-341.

810 Kaspari M, Weiser MD. 1999. The size-grain hypothesis and interspecific scaling in ants. $811 \quad$ Functional Ecology 13:530-538.

812 Koptur, S. 1992. Interactions between insects and plants mediated by extrafloral nectaries. In: 813 Bernays E. Insect-Plant Interactions (4), p. 85-132. Insect/Plant Interactions. CRC Press. 814 Lach L, \& Hooper-Bui, LM. 2010. Consequences of ant invasions. In: Lach L, Parr CL, Abbott 815 KL eds. Ant ecology, Oxford, UK: Oxford University Press, 261-286.

816 Lange D, Dáttilo W, Del-Claro K. 2013. Influence of extrafloral nectary phenology on ant-plant 817 mutualistic networks in a neotropical savanna. Ecological Entomology 38:463-469.

818 LeBrun EG. 2005. Who is the top dog in ant communities? Resources, parasitoids, and multiple 819 competitive hierarchies. Oecologia 142:643-652.

820 López-Carretero A, Díaz-Castelazo C, Boege K, Rico-Gray V. 2014. Evaluating the Spatio821 Temporal Factors that Structure Network Parameters of Plant-Herbivore Interactions. PLoS 822 ONE 9: e110430.

823 Majer JD. 1993. Comparison of the arboreal ant mosaic in Ghana, Brazil, Papua New Guinea 824 and Australia - its structure and influence on arthropod diversity. In: LaSalle J, Gauld ID 825 eds. Hymenoptera and biodiversity, Wallingford, UK: CAB International, 115-141. 
826 Marquitti FMD, Guimaraes PR, Pires MM, Bittencourt LF. 2014. MODULAR: Software for the

827 autonomous computation of modularity in large network sets. Ecography 37:221-224.

828 Martínez-Adriano CA, Aguirre-Jaimes A, Díaz-Castelazo C. 2016. Floristic survey of flowering 829 plants in a tropical coastal ecosystem in Veracruz, Mexico. Botanical Sciences 94:185-197.

830 Martínez-Adriano CA. 2017. Fenología reproductiva de angiospermas, producción de flores y

831 visitantes florales en un ecosistema costero en Veracruz, México. Ph.D. Thesis, Instituto de 832 Ecología, A. C.

833 McGlynn TP. 1999. The worldwide transfer of ants: geographical distribution and ecological 834 invasions. Journal of Biogeography 26:535-548.

835 Memmott J, Waser NM, Price MV. 2004. Tolerance of pollination networks to species

836 extinctions. Proceedings of the Royal Society of London B: Biological Sciences, 271(1557):

$837 \quad 2605-2611$.

838 Moreno-Casasola P. 1982. Ecología de la vegetación de dunas costeras: factores

839 físicos. Biotica 7:577-602.

840 Moreno-Casasola P, Travieso-Bello AC. 2006. Las playas y dunas. In: Moreno-Casasola ed.

841 Entornos Veracruzanos: la costa de La Mancha. Instituto de Ecología, A.C., México.

842 Nepi, M. 2007. Nectary structure and ultrastructure. In Nectaries and nectar. pp. 129-166.

$843 \quad$ Springer, Dordrecht.

844 Ness JH, Bronstein JL. 2004. The effects of invasive ants on prospective ant mutualists.

845 Biological Invasions 6:445-461.

846 Oksanen J. 2009. Vegan: an introduction to ordination. R statistical software. 'R group'.

847 Olesen JM, Bascompte J, Dupont YL, Jordano P. 2007. The modularity of pollination networks.

848 Proceedings of the National Academy of Sciences of the United States of America 
104:19891-19896.

850 Oliveira PS, Rico-Gray V, Díaz-Castelazo C, Moreno-Casasola -Guevara C. 1999. Interaction

851 between ants, extrafloral nectaries and insect herbivores in Neotropical coastal sand dunes:

852 herbivore deterrence by visiting ants increases fruit set in Opuntia stricta Cactaceae.

$853 \quad$ Functional Ecology 13:623-631.

854 Parr CL, Gibb H. 2010. Competition and the role of dominant ants. In: Lach L, Parr CL, Abbott 855 KL eds. Ant ecology, Oxford, UK: Oxford University Press, 77-96.

856 Pérez-Maqueo O. 1995. Análisis del efecto de los disturbios en la dinámica de la playa de El 857 Morro de La Mancha, Veracruz. México DF: UNAM.

858 Pimm SL, Lawton JH. 1980. Are food webs divided into compartments?. The Journal of Animal $859 \quad$ Ecology 49:879-898.

860 Poisot T, Stouffer DB, Gravel D. 2015. Beyond species: why ecological interaction networks $861 \quad$ vary through space and time. Oikos 124(3): 243-251.

862 Quinn GP, Keough MJ. 2002. Experimental design and data analysis for biologists. Cambridge $863 \quad$ University Press.

864 R Core Team. 2014. R: A language and environment for statistical computing. R Foundation for 865 Statistical Computing, Vienna, Austria. URL: http://www.R-project.org/.

866 Radhika V, Kost C, Mithöfer A, Boland W. 2010. Regulation of extrafloral nectar secretion by 867 jasmonates in lima bean is light dependent. Proceedings of the National Academy of 868 Sciences of the United States of America 107(4):17228-17233.

869 Ramos-Robles M, Andresen E, Díaz-Castelazo C. 2016. Temporal changes in the structure of a 870 plant-frugivore network are influenced by bird migration and fruit availability. PeerJ 4:e2048. doi:10.7717/peerj.2048. 
872 Rezende, EL, Jordano P, Bascompte J. 2007. Effects of phenotypic complementarity and 873 phylogeny on the nested structure of mutualistic networks. Oikos 116(11): 1919-1929.

874 Rezende EL, Lavabre JE, Guimarães PR, Jordano P, Bascompte J. 2007. Non-random

875 coextinctions in phylogenetically structured mutualistic networks Nature 448:9257-9259.

876 Rico-GrayV, Barber JT, Thien LB, Ellgaard EG, Toney JJ. 1989. An Unusual Animal-Plant

877 Interaction: Feeding of Schomburgkia tibicinis (Orchidaceae) by ants. American Journal of $878 \quad$ Botany $76: 603-608$.

879 Rico-Gray V. 1993. Use of plant-derived food resources by ants in the dry tropical lowlands of 880 coastal Veracruz, Mexico. Biotropica 25:301-315.

881 Rico-Gray V, Oliveira PS. 2007. The ecology and evolution of ant-plant interactions. University 882 of Chicago Press.

883 Rico-Gray V, Díaz-Castelazo C, Ramírez-Hernández A, Guimarães PR, Holland JN. 2012.

884 Abiotic factors shape temporal variation in the structure of an ant-plant network. 885 Arthropod-Plant Interactions 6:289-295.

886 Rudgers JA, 2004. Enemies of herbivores can shape plant traits: selection in a facultative ant887 plant mutualism. Ecology 85:192-201.

888 Rudgers JA, Gardener MC. 2004. Extrafloral nectar as a resource mediating multispecies 889 interactions. Ecology 85:1495-1502.

890 Sánchez-Galván IR, Díaz-Castelazo C, Rico-Gray V. 2012. Effect of Hurricane Karl on a plant891 ant network occurring in coastal Veracruz, Mexico. Journal of Tropical Ecology 28:603$892 \quad 609$.

893 Schultz TR, McGlynn TP. 2000. The interactions of ants with other organisms. In: Agosti D, 894 Majer J.D. Alonso LE, Schultz TR. Ants: standard methods for measuring and monitoring 
biodiversity. Washington: Smithsonian Institution Press,35-44.

896 Stang M, Klinkhamer PGL, van der Meijden E, Memmott J. 2006. Size constraints and flower 897 abundance determine the number of interactions in a plant-flower visitor web. Oikos 112:111-121.

Stang M. 2007. Asymmetric specialization and extinction risk in plant-flower visitor webs: a 900 matter of morphology or abundance? Oecologia 151:442-453.

901 Thébault E, Fontaine C. 2010. Stability of ecological communities and the architecture of 902 mutualistic and trophic networks. Science 329:853-856.

903 Thompson JN 2005. The geographic mosaic of coevolution. University of Chicago Press, $904 \quad$ Chicago.

905 Vázquez DP, Aizen MA. 2004. Asymmetric specialization: a pervasive feature of plant906 pollinator interactions. Ecology 85:1251-1257.

907 Vázquez DP, Morris WF, Jordano P. 2005. Interaction frequency as a surrogate for the total 908 effect of animal mutualists on plants. Ecology Letters 8:1088-1094.

909 Vázquez DP, Melián CJ, Williams NM, Blüthgen N, Krasnov BR, Poulin R. 2007. Species 910 abundance and asymmetric interaction strength in ecological networks. Oikos 116:1120$911 \quad 1127$

912 Vázquez DP, Blüthgen N, Cagnolo L, Chacoff NP. 2009. The determinants of patterns in 913 mutualistic networks: a review. Annals of Botany 103:1445-1457.

914 Vázquez DP, Chacoff NP, Cagnolo L. 2009. Evaluating multiple determinants of the structure of 915 plant-animal mutualistic networks. Ecology 90:2039-2046.

916 Wäckers FL, Bonifay C. 2004. How to be sweet? Extrafloral nectar allocation by Gossypium 917 hirsutum fits optimal defense theory predictions. Ecology 85:1512-1518. 
918 Yamawo A, Hada Y. 2010. Effects of light on direct and indirect defences against herbivores of

919 young plants of Mallotus japonicus demonstrate a trade-off between two indirect defence

$920 \quad$ traits. Annals of Botany 106:143-148.

921

922 
923 Table 1. EFN-bearing plant species within the network and its attributes. Plant attributes considered also

924 in Figure 2 are: EFN= Distribution of extrafloral nectaries within a plant species (' $\mathrm{C}$ ' are circumscribed

925 glands and ' $D$ ' are disperse glands). Habitat= distribution of plant species between habitats with

926 contrasting vegetation structure (' $\mathrm{S}$ ' is shaded vegetation and ' $\mathrm{O}$ ' is open vegetation). Abundance $=$

927 percentage cover of EFN-bearing plant species.

928

\begin{tabular}{|c|c|c|c|c|}
\hline Plant species & $\begin{array}{l}\text { Plant species } \\
\text { code }\end{array}$ & $\begin{array}{l}\text { Distribution of } \\
\text { EFNs }\end{array}$ & $\begin{array}{l}\text { Habitat } \\
\text { structure }\end{array}$ & $\begin{array}{c}\text { Abundance } \\
\text { (\%cover) }\end{array}$ \\
\hline Cordia spinescens & CorSpi & $\mathrm{D}$ & $\mathrm{S}$ & 38.833 \\
\hline Turnera ulmifolia & TurUlm & $\mathrm{C}$ & $\mathrm{O}$ & 6.66 \\
\hline Crotalaria indica & CrotIn & $\mathrm{C}$ & $\mathrm{O}$ & 12.38 \\
\hline Cedrela odorata & CedOdo & $\mathrm{D}$ & $\mathrm{S}$ & 36.143 \\
\hline Callicarpa acuminata & CallAc & $\mathrm{D}$ & B & 68.797 \\
\hline Caesalpinia crista & CaeCri & $\mathrm{C}$ & $\mathrm{O}$ & 27.15 \\
\hline Bidens pilosa & BidPil & $\mathrm{C}$ & $\mathrm{S}$ & 27.95 \\
\hline Canavalia rosea & CanRos & $\mathrm{C}$ & $\mathrm{O}$ & 76.057 \\
\hline Calopogonium caeruleum & CalCae & $\mathrm{C}$ & $\mathrm{O}$ & 16.85 \\
\hline Terminalia catappa & TerCat & $\mathrm{C}$ & $\mathrm{S}$ & 0.35 \\
\hline Senna occidentalis & SenOcc & $\mathrm{C}$ & $\mathrm{S}$ & 3.717 \\
\hline Opuntia stricta & OpuStri & $\mathrm{D}$ & $\mathrm{O}$ & 64.35 \\
\hline Hibiscus tiliaceus & HibTill & $\mathrm{C}$ & $\mathrm{O}$ & 2.4 \\
\hline $\begin{array}{l}\text { Amphilophium } \\
\text { paniculatum }\end{array}$ & AmphPa & $\mathrm{D}$ & $\mathrm{O}$ & 17.55 \\
\hline Ipomoea pescaprae & IpoPes & $\mathrm{C}$ & $\mathrm{O}$ & 49.1 \\
\hline Conocarpus erectus & ConEre & $\mathrm{C}$ & S & 16.383 \\
\hline Ficus obtusifolia & FicObt & $\mathrm{C}$ & S & 8.15 \\
\hline Cornutia grandiflora & CorGra & $\mathrm{D}$ & $\mathrm{O}$ & 2.5 \\
\hline
\end{tabular}




$\begin{array}{ccccc}\begin{array}{c}\text { Macroptilium } \\ \text { atropurpureum }\end{array} & \text { MacAtr } & \text { C } & \text { O } & 16.3 \\ \text { Cissus rhombifolia } & \text { CisRho } & \text { C } & \text { O } \\ \text { Ipomoea sp. } & \text { IpoSp. } & \text { C } & \text { S } & 3.55 \\ \text { Mansoa hymenaea } & \text { ManHym } & \text { C } & \text { S } & 12.167 \\ \text { Tabebuia rosea } & \text { TabRos } & \text { D } & \text { S } & 16.3 \\ \text { Acacia macracantha } & \text { AcaMac } & \text { C } & \text { B } & 6.66 \\ \text { Trichilia havanensis } & \text { TriHav } & \text { C } & \text { S } & 2.75 \\ \text { Arundo donax } & \text { AruDon } & \text { C } & \text { O } & 28.33 \\ \text { Petrea volubilis } & \text { PetVol } & \text { D } & \text { O } & 151.66 \\ \text { Chamaecrista } & \text { ChaCha } & \text { C } & \text { O } & 74.1 \\ \text { chamaecristoides } & & & & 32.4 \\ \text { Iresine celosia } & \text { IreCel } & \text { C } & \text { O } & \\ \text { Cordia dentata } & \text { CorDen } & \text { D } & \text { S } & 16.55 \\ \text { Bunchosia lindeliana } & \text { BunLin } & \text { C } & \text { S } & 3.615\end{array}$

929

930

931

932

933

934

935

936

937

938

939 
940 Table 2. Ant species within the network and its attributes. Ant attributes considered also in Figure 2 are:

941 invasive status $=$ status as invasive/tramp ant species $($ INV or NO), Dominance $=$ hierarchies of

942 behavioral dominance (from the most dominant to the least) are: $\mathrm{A}=$ Dominant Dolichoderine, $\mathrm{B}=$

943 Generalized Myrmicine, $\mathrm{C}=$ Subordinate Camponotini, $\mathrm{D}=$ Tropical Climate Specialists, $\mathrm{E}=$

944 Opportunistic, F= Specialist Predators; Head length= length ( $\mathrm{mm})$ from head apex to anterior clypeal

945 margin of species (minor worker).

946

\begin{tabular}{|c|c|c|c|c|}
\hline Ant species & $\begin{array}{l}\text { Ant species } \\
\text { code }\end{array}$ & Invasive status & Dominance hierarchy & Head length \\
\hline $\begin{array}{l}\text { Camponotus } \\
\text { planatus }\end{array}$ & CamPla & $\mathrm{NO}$ & $\mathrm{C}$ & 1.198 \\
\hline $\begin{array}{l}\text { Camponotus } \\
\text { mucronatus }\end{array}$ & CamMu & NO & $\mathrm{C}$ & 1.418 \\
\hline $\begin{array}{l}\text { Camponotus } \\
\text { atriceps }\end{array}$ & $\operatorname{CamAt}$ & NO & $\mathrm{C}$ & 1.946 \\
\hline Azteca sp. 1 & AztSp & NO & A & 1.471 \\
\hline $\begin{array}{c}\text { Paratrechina } \\
\text { longicornis }\end{array}$ & ParLo & INV & $\mathrm{E}$ & 0.638 \\
\hline $\begin{array}{l}\text { Tetramorium } \\
\text { spinosum }\end{array}$ & TetSpi & INV & $\mathrm{E}$ & 0.968 \\
\hline $\begin{array}{c}\text { Cephalotes } \\
\text { minutus }\end{array}$ & CepMin & NO & $\mathrm{D}$ & 1.155 \\
\hline $\begin{array}{l}\text { Dorymyrmex } \\
\text { bicolor }\end{array}$ & DorBi & NO & A & 0.973 \\
\hline $\begin{array}{l}\text { Pseudomyrmex } \\
\text { gracilis }\end{array}$ & PseGra & NO & $\mathrm{F}$ & 1.738 \\
\hline $\begin{array}{l}\text { Monomorium } \\
\text { cyaneum }\end{array}$ & MonCy & NO & $\mathrm{B}$ & 0.482 \\
\hline $\begin{array}{l}\text { Camponotus } \\
\text { mucronatus } \\
\text { hirsutinasus }\end{array}$ & CamHi & NO & $\mathrm{C}$ & 1.076 \\
\hline $\begin{array}{c}\text { Pachycondyla } \\
\text { villosa }\end{array}$ & PachVi & NO & $\mathrm{F}$ & 2.880 \\
\hline Forelius analis & ForAna & NO & $\mathrm{A}$ & 0.631 \\
\hline $\begin{array}{c}\text { Crematogaster } \\
\text { brevispinosa }\end{array}$ & CreBre & NO & $\mathrm{B}$ & 1.031 \\
\hline Pheidole sp. & PheSp & $\mathrm{NO}$ & $\mathrm{B}$ & 0.553 \\
\hline $\begin{array}{c}\text { Solenopsis } \\
\text { geminata }\end{array}$ & SolGe & INV & $\mathrm{D}$ & 0.684 \\
\hline $\begin{array}{l}\text { Wassmannia } \\
\text { auropunctata }\end{array}$ & WasAu & INV & $\mathrm{D}$ & 0.479 \\
\hline Pseudomyrmex & PseEje & NO & $\mathrm{F}$ & 0.800 \\
\hline
\end{tabular}


ejectus

$\begin{array}{lllll}\text { Pseudomyrmex } & \text { PseBru } & \text { NO } & \text { F } & 0.768\end{array}$ brunneus

947

948

949 FIGURE LEGENDS

950

951 Figure 1. Quantitative mutualistic networks between EFN-bearing plants (lower trophic level, 952 green nodes) and ant visitor species (higher trophic level, red nodes). Blue-colored nodes depict 953 species constituting the core of the network. Species codes as in Tables 1 and 2.

954

955

Figure 2. Ordination of NMDS representing the assemblage of interactions given the ant-plant distances (Bray-Curtis) at the network. Plant species in black; ant species in red. Species names appear as in Tables 1 and 2: at the ordination, first plant species (P1), second plant species (P2) and so on, correspond to the first plant species, and the second plant species in Table 1 and so on. First ant species (A1), second ant species (A2) and so on, correspond to the first ant species, and the second ant species in Table 2 and so on. NMDS Stress $=0.17$ (fourth iteration) indicates a good two-dimensional solution of the ordination suitably representing ant-plant assemblage dissimilarity; this configuration also has very low residuals $(\max$ res $=0.0004)$ showing a good concordance between the calculated dissimilarities and the distances among objects. Nonoverlapping ellipses (i.e. orange and green) circle the attribute (factor) that significantly explained $\left(r^{2}=0.24, P=0.005\right)$ the pairwise interaction pattern (habitat types). 
971 Figure 1.

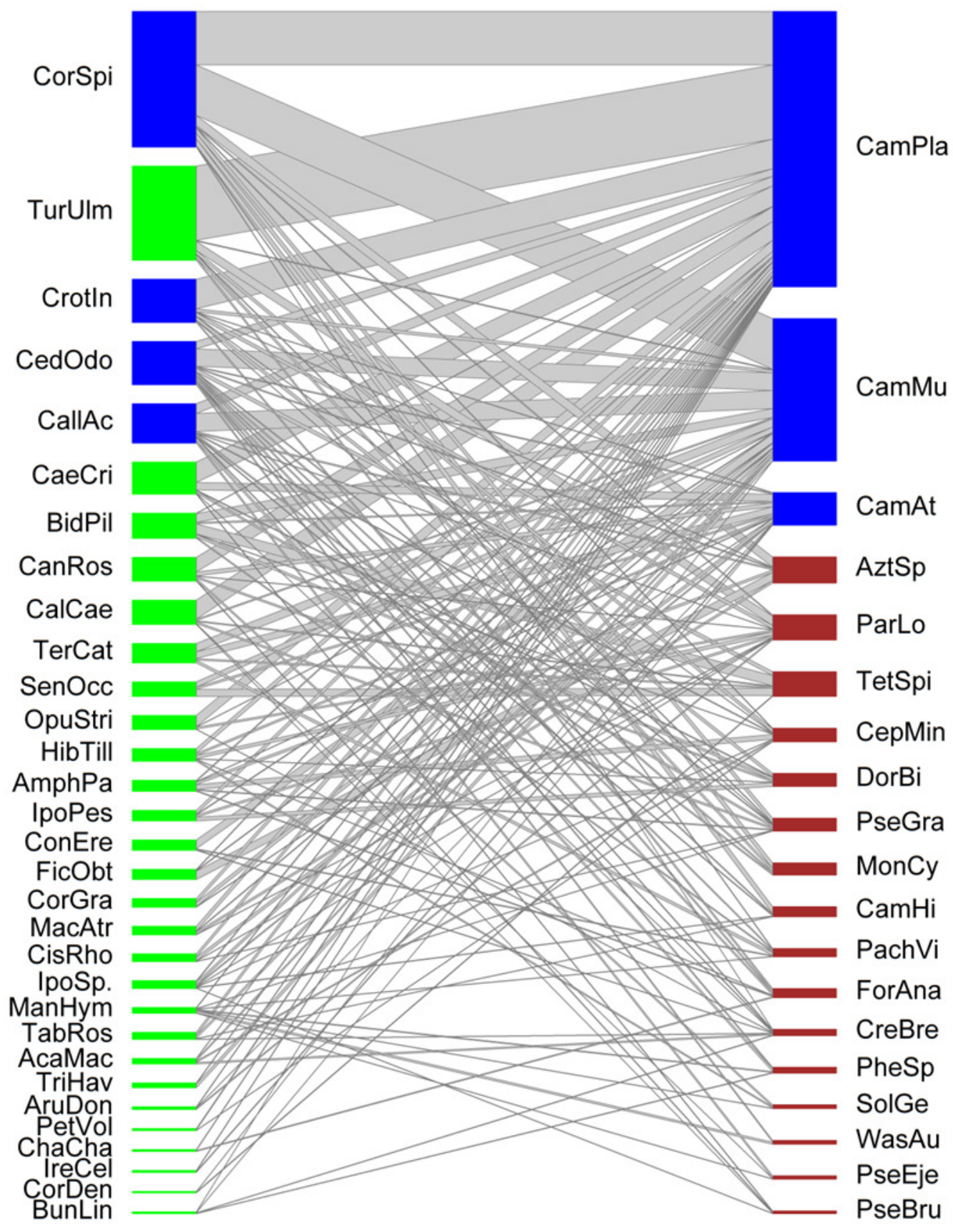


973

974 Figure 2.

975

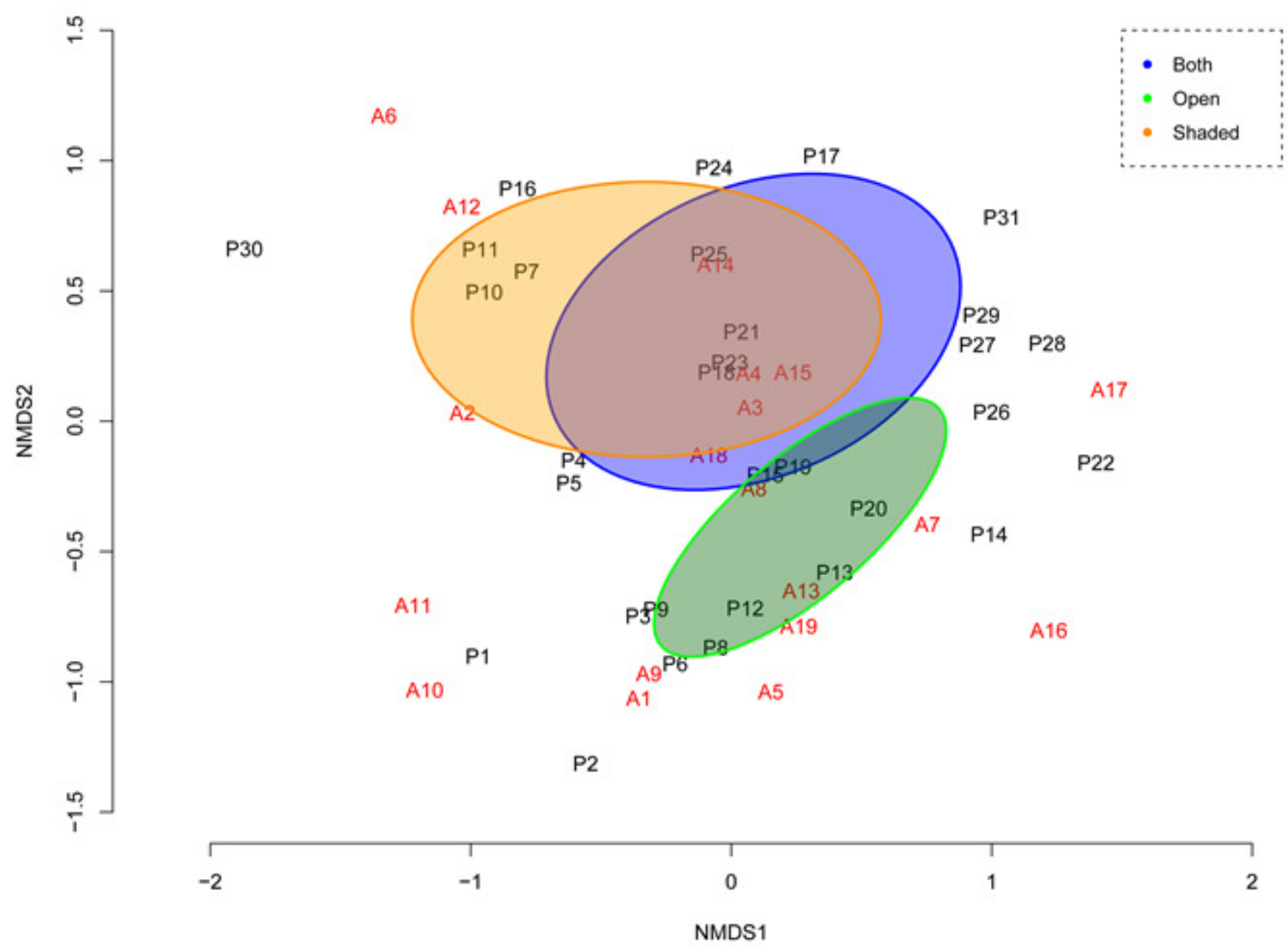

976

977

978

979

980 